\title{
Meta-analysis of elective high frequency ventilation in preterm infants with respiratory distress syndrome
}

\author{
Filip Cools, Martin Offringa
}

\begin{abstract}
Aim-To summarise the evidence on the efficacy of elective high frequency ventilation compared with conventional ventilation in preterm infants with respiratory distress syndrome.

Methods-A search from 1987 onwards was made on Embase, Medline, and the Cochrane Library. A questionnaire was also circulated during an international meeting on high frequency ventilation. To be included in the data synthesis, studies had to be randomised controlled trials comparing elective high frequency ventilation with conventional ventilation in preterm infants with respiratory failure due to respiratory distress syndrome; indices of mortality, chronic pulmonary morbidity, and other clinically relevant outcomes were compared. Studies were assessed for methodological validity according to explicit criteria.

Results-Ten studies (a total number of 1345 preterm infants) were considered for data synthesis. No difference in mortality at 28 or 30 days, nor in oxygen dependency at 28 days was found between both types of ventilation. Reduced oxygen dependency at the postconceptional age of 36 weeks (RR 0.50, 95\% CI 0.32-0.78) was found, but so was an increase in grades 3 and 4 intraventricular haemorrhage (IVH) (RR 1.31, 95\% CI 1.04-1.66). Those studies using a high lung volume ventilatory strategy showed a significant decrease in oxygen dependency at the postconceptional age of 36 weeks (RR 0.44, 95\% CI 0.27-0.73), but no increase in severe IVH (RR $0.78,95 \%$ CI 0.45-1.37).
\end{abstract}

Conclusions-Although high frequency ventilation reduces chronic lung disease, it seems to increase the risk of severe IVH. These results are dominated by an early study where the absence of benefit on pulmonary outcomes, and the increase in adverse neurological events, could be related to the low volume ventilatory strategy used. Recent studies, using a high lung volume approach, show better pulmonary outcomes without any increase in intracranial morbidity. Still, uncertainty remains about long term pulmonary and neurodevelopmental outcome.

(Arch Dis Child Fetal Neonatal Ed 1999;80:F15-F20)

Keywords: elective high frequency ventilation; respiratory distress syndrome; intraventricular haemorrhage
Despite advances in management, such as the use of surfactant, the mortality and morbidity of respiratory distress syndrome in premature infants remain high. Chronic pulmonary morbidity after mechanical ventilation is still a major clinical problem. In particular, very low birthweight infants are at high risk of chronic lung disease: at least one in four infants between 500 and $750 \mathrm{~g}$ is oxygen dependent at the postconceptional age of 36 weeks. ${ }^{1}$ It is now thought that this lung damage is largely caused by repetitive collapse and overexpansion of surfactant deficient lungs, creating shear forces, with subsequent epithelial injury and inflammatory responses. ${ }^{23}$ In an attempt to avoid such lung injury alternative ventilation modalities were examined.

High frequency ventilation (HFV) was first described by Bohn et al in 1980. ${ }^{4}$ Animal studies showed that it could obtain effective gas exchange ${ }^{4}$ and, if started soon after birth, was associated with less lung injury. ${ }^{5}$ The first large randomised trial in human infants investigating the efficacy and safety of HFV as the primary treatment of respiratory distress syndrome (RDS), the HIFI trial in $1989,{ }^{6}$ failed to show any advantage in pulmonary outcome when compared with conventional ventilation. On the contrary, the safety of HFV was a cause for concern, as it seemed to be associated with an increase in adverse neurological eventsnamely, intraventricular haemorrhage and possibly periventricular leucomalacia. Several smaller clinical trials have followed, of which some demonstrated a beneficial effect of HFV and others not. ${ }^{7-11}$

Recently Bhuta and Henderson-Smart published a meta-analysis of four studies comparing elective high frequency oscillatory ventilation (HFOV) with conventional ventilation in preterm infants with respiratory failure. ${ }^{12}$ They showed that, overall, there was no significant difference in oxygen dependency at 28 days between either type. They also mentioned that the HIFI trial dominated the results. Of the four studies, only two more recent trials used the HLVS. These trials showed better results for pulmonary outcomes. This review includes additional and more recent studies and adopts a different approach by initially pooling all different types of HFV-high frequency oscillation, high frequency jet ventilation, and high frequency flow interruption.

To investigate the current virtues of elective $\mathrm{HFV}$ compared with conventional ventilation in the treatment of RDS in preterm infants, we performed a meta-analysis of all published 
Table 1 Characteristics of trials incuded in this review

\begin{tabular}{|c|c|c|c|c|c|c|c|c|}
\hline Reference & HFV type & Ventilator type & $H L V S^{\star}$ & Surfactant & $\begin{array}{l}\text { No of } \\
\text { patients }\end{array}$ & $\begin{array}{l}\text { Mean birthweight } \\
(\mathrm{kg})\end{array}$ & $\begin{array}{l}\text { Mean gestational } \\
\text { age (weeks) }\end{array}$ & $\begin{array}{l}\text { Mean age HFV } \\
\text { started (hours) }\end{array}$ \\
\hline Froese, $1987^{16}$ & HFOV & HSMVB, (Metrex Instruments) & No & No & 15 & $1.1(0.8)$ & $28(1)$ & Not reported \\
\hline HIFI, $1989^{6}$ & HFOV & $\begin{array}{l}\text { Hummingbird, (Senko Medical } \\
\text { Instrument Manufacturing) }\end{array}$ & No & No & 673 & $1.1(0.3)$ & $28(2)$ & $6(0.5)$ \\
\hline Carlo, $1990^{17}$ & HFJV & Self constructed & No & No & 42 & $1.4(0.3)$ & $30(2)$ & $15(4-30) \dagger$ \\
\hline Clark, $1992^{7}$ & HFOV & Sensormedics 3100, (Sensormedics) & Yes & No & 83 & $1.1(0.3)$ & $28(3)$ & $9(5)$ \\
\hline Ogawa, $1993^{8}$ & HFOV & $\begin{array}{l}\text { Hummingbird BMO } 20 \mathrm{~N} \text {, (Senko } \\
\text { Medical Instruments Manufacturing) }\end{array}$ & Yes & Yes & 92 & $1.2(0.3)$ & $29(2)$ & $2(2)$ \\
\hline Gerstmann, $1996^{9}$ & HFOV & Sensormedics 3100 (A), (Sensormedics) & Yes & Yes & 125 & $1.5(0.5)$ & $31(2)$ & $3(1)$ \\
\hline Wiswell, $1996^{23}$ & HFJV & Life Pulse HFJV, (Bunnell Inc) & No & Yes & 73 & $0.9(0.3)$ & $27(2)$ & $7(5)$ \\
\hline Keszler, $1997^{10}$ & HFJV & Life Pulse HFJV (Bunnell Inc) & Yes & Yes & 130 & $1.0(0.2)$ & $27(2)$ & $8(4)$ \\
\hline Rettwitz-Volk ${ }^{25}$ & HFOV & $\begin{array}{l}\text { Stephan SHF } 3000 \text {, } \\
\text { (F Stephan Medizintechnik) }\end{array}$ & No & Yes & 96 & $1.1(0.1)$ & $28(1)$ & $1(0.5)$ \\
\hline Plavka $^{11}$ (in press) & HFOV & Sensormedics 3100A (Sensormedics) & Yes & Yes & 43 & $0.85(0.2)$ & $26(2)$ & Not reported $\ddagger$ \\
\hline
\end{tabular}

All values are expressed as mean (SD); * HLVS: high lung volume strategy; $\uparrow$ as described by Carlo WA et al in $\mathcal{f}$ Pediatr 1984;104:101-7 and by Carlon GC et al in Crit Care Med 1981;9:47-50. † Value expressed as mean (range); $\ddagger$ Ventilatory stabilisation on assigned ventilator mode according to the protocol within 3 hours after birth. HFV=high frequency ventilation; HFOV=high frequency oscillatory ventilation; HFJV=high frequency jet ventilation; $\mathrm{CV}=$ conventional ventilation; $\mathrm{RDS}=$ respiratory distress syndrome; $\mathrm{BPD}=$ bronchopulmonary dysplasia; $\mathrm{CLD}=$ chronic lung disease; HLVS=high lung volume strategy; $\mathrm{RR}=$ relative risk;

randomised controlled trials on this issue. We also identified current areas of uncertainty, which constitute possible issues for future studies.

\section{Methods}

Two databases, Medline (from 1987 onwards) and Embase (from 1988 onwards), were searched using the terms high frequency ventilation and high frequency jet ventilation. From the search results all randomised trials comparing the use of high frequency ventilation with conventional ventilation in neonates were selected. References of previous reviews were searched manually for trials not present in the database search. The Cochrane Library was also consulted. ${ }^{13}$ Information concerning unpublished trials or completed trials awaiting publication was obtained directly from experts in the field during an international meeting on $\mathrm{HFV}$ in October 1997 in Ovifat (Belgium).

To be included in the meta-analysis the studies had to meet the following criteria: (1) the study was a randomised controlled trial; (2) the study patients were preterm infants of less than 35 weeks of gestational age or with birthweights of less than $2000 \mathrm{~g}$ and with respiratory failure due to respiratory distress syndrome; (3) the intervention was the elective use of high frequency ventilation-high frequency oscillation (HFOV), high frequency jet ventilation (HFJV) or high frequency flow interruption (HFFI), started within 24 hours of birth, compared with conventional ventilation; and (4) the primary aim of the study was to keep the study patients on the assigned treatment during the whole course of the disease.
The trials were assessed for methodological validity according to the guidelines of the Cochrane Collaboration by examining them on four possible biases. The question of selection bias - whether there are systematic differences in comparison groups-was answered by assessing randomisation methods. Performance bias, questioning systematic differences in care provided, apart from the intervention being evaluated, was ruled out if care providers were blinded for the intervention and if cointervention bias was avoided. The latter is attained if detailed guidelines for general patient care, apart from the intervention, were integrated in the study protocol. Attrition bias, caused by systematic differences in withdrawal from the trial, was considered to be present if more than $10 \%$ of the study patients had been lost for results and follow up. Detection bias was assessed by investigating blinding of outcome assessment. Data on the following outcomes were extracted: mortality at 28 to 30 days of age; bronchopulmonary dysplasia (BPD), defined as oxygen dependency at the age of 28 to 30 days with radiological evidence of BPD, and chronic lung disease (CLD), defined as oxygen dependency at the postconceptional age of 36 weeks; intraventricular haemorrhage (IVH), all grades, and grades 3 (IVH with distended ventricles) and 4 (with intraparenchymatous echodensity); periventricular leucomalacia (PVL); air leak syndrome (ALS), defined as gross air leak (pneumothorax, pneumomediastinum, pneumopericardium or pneumoperitoneum) and/or pulmonary interstitial emphysema (PIE); total

Table 2 Methodological validity of included trials

\begin{tabular}{|c|c|c|c|c|c|c|c|}
\hline \multirow[b]{2}{*}{ Reference } & \multicolumn{2}{|l|}{1 Selection bias } & \multicolumn{3}{|c|}{2 Performance bias } & \multirow{2}{*}{$\begin{array}{l}3 \text { Attrition bias } \\
<10 \% \\
\text { withdrawal }\end{array}$} & \multirow{2}{*}{$\begin{array}{l}4 \text { Detection bias } \\
\begin{array}{l}\text { Blinding outcome } \\
\text { assessment }\end{array}\end{array}$} \\
\hline & Randonisation & $\begin{array}{l}\text { Concealed } \\
\text { allocation }\end{array}$ & $\begin{array}{l}\text { Blinding } \\
\text { intervention }\end{array}$ & $\begin{array}{l}\text { Co-intervention } \\
\text { avoided }\end{array}$ & Centres & & \\
\hline Froese $^{16}$ & Not described & Uncertain & No & Yes & 1 & No & No \\
\hline $\mathrm{HIFI}^{6}$ & Computer & Uncertain & No & Yes & 11 & Yes & Head US^ \\
\hline Carlo $^{17}$ & Envelopes & Uncertain & No & Uncertain & 1 & Yes & No \\
\hline Clark $^{7}$ & Blind card draw & Uncertain & No & Uncertain & 1 & Yes & Head US + CXR† \\
\hline Ogawa $^{8}$ & Envelopes & Uncertain & No & Yes & 9 & Yes & Head US + CXR \\
\hline Gerstmann $^{9}$ & Blind card draw & Uncertain & No & Uncertain & 3 & Yes & No \\
\hline $\mathrm{W}$ iswell $^{23}$ & Envelopes & Uncertain & No & Uncertain & 1 & Yes & Head US \\
\hline Keszler $^{10}$ & Envelopes & Uncertain & No & No & 8 & Yes & No \\
\hline Rettwitz-Volk ${ }^{25}$ & Computer & Uncertain & No & Uncertain & 3 & Yes & No \\
\hline Plavka $^{11}$ & Envelopes & Uncertain & No & Uncertain & 1 & Yes & CXR \\
\hline
\end{tabular}

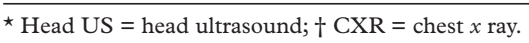


Table 3. Mortality at 28 to 30 days: high frequency ventilation (HFV) versus conventional ventilation $(C V)$

\begin{tabular}{llll}
\hline $\begin{array}{l}\text { Reference } \\
\text { Froese, } 1987\end{array}$ & $\begin{array}{l}\text { HFV event observed/ } \\
\text { total No of patients }\end{array}$ & $\begin{array}{l}\text { CV event observed/ } \\
\text { total No of patients }\end{array}$ & $\begin{array}{l}\text { Relative risk } \\
\text { (95\% CI) }\end{array}$ \\
HIFI, 1989 & $2 / 5$ & $3 / 9$ & $1.20(0.29,4.95)$ \\
Carlo, 1990 & $60 / 327$ & $60 / 346$ & $1.06(0.77,1.46)$ \\
Clark, 1992 & $4 / 21$ & $5 / 21$ & $0.80(0.25,2.57)$ \\
Ogawa, 1993 & $5 / 30$ & $3 / 26$ & $1.44(0.38,5.47)$ \\
Gerstmann, 1996 & $0 / 46$ & $1 / 46$ & $0.33(0.01,7.98)$ \\
Wiswell, 1996 & $0 / 64$ & $2 / 61$ & $0.19(0.01,3.90)$ \\
Rettwitz-Volk, 1998 & $6 / 37$ & $4 / 36$ & $1.46(0.45,4.75)$ \\
Total for all studies & $5 / 46$ & $5 / 50$ & $1.09(0.34,3.51)$ \\
Total for HLVS subgroup & $82 / 576$ & $83 / 595$ & $1.04(0.79,1.37)$ \\
Total for surfactant subgroup & $11 / 140$ & $6 / 133$ & $0.77(0.27,2.22)$ \\
Total for HFOV subgroup & $72 / 518$ & $12 / 193$ & $0.94(0.45,1.98)$ \\
Total for HFJV subgroup & $10 / 58$ & $74 / 538$ & $1.04(0.77,1.39)$ \\
\hline
\end{tabular}

$\mathrm{HFV}=$ high frequency ventilation; $\mathrm{HFOV}=$ high frequency oscillatory ventilation; $\mathrm{HFJV}=$ high frequency jet ventilation; $\mathrm{CV}=$ conventional ventilation; $\mathrm{RDS}=$ respiratory distress syndrome; $\mathrm{BPD}=$ bronchopulmonary dysplasia; $\mathrm{CLD}=$ chronic lung disease; HLVS=high lung volume strategy; $\mathrm{RR}=$ relative risk; $\mathrm{CI}=$ confidence interval.

Table 4 Bronchopulmonary dysplasia: high frequency ventilation (HFV) versus conventional ventilation $(C V)$

\begin{tabular}{llll}
\hline Reference & $\begin{array}{l}\text { HFV event observed/ } \\
\text { total No of patients }\end{array}$ & $\begin{array}{l}\text { CV event observed } \\
\text { /total No of patients }\end{array}$ & $\begin{array}{l}\text { Relative risk } \\
\text { (95\% CI) }\end{array}$ \\
\hline Froese, 1987 & $0 / 6$ & $2 / 9$ & $0.29(0.02,5.08)$ \\
HIFI, 1989 & $130 / 327$ & $141 / 346$ & $0.98(0.81,1.17)$ \\
Carlo, 1990 & $7 / 18$ & $7 / 16$ & $0.89(0.04,1.98)$ \\
Clark, 1992 & $9 / 30$ & $17 / 26$ & $0.46(0.25,0.85)$ \\
Ogawa, 1993 & $17 / 46$ & $15 / 46$ & $1.13(0.65,1.99)$ \\
Gerstmann, 1996 & $15 / 64$ & $27 / 61$ & $0.53(0.31,0.89)$ \\
Wiswell, 1996 & $21 / 37$ & $23 / 36$ & $0.89(0.61,1.29)$ \\
Keszler, 1997 & $37 / 55$ & $37 / 52$ & $0.95(0.73,1.22)$ \\
Rettwitz-Volk, 1998 & $18 / 21$ & $14 / 20$ & $1.22(0.88,1.71)$ \\
Total for all studies & $254 / 604$ & $283 / 612$ & $0.90(0.80,1.02)$ \\
Total for HLVS subgroup & $96 / 216$ & $110 / 205$ & $0.83(0.69,0.99)$ \\
Total for surfactant subgroup & $108 / 223$ & $116 / 215$ & $0.89(0.75,1.06)$ \\
Total for HFOV subgroup & $189 / 494$ & $216 / 508$ & $0.90(0.77,1.04)$ \\
Total for HFJV subgroup & $65 / 110$ & $67 / 104$ & $0.92(0.75,1.13)$ \\
\hline
\end{tabular}

$\mathrm{HFV}=$ high frequency ventilation; $\mathrm{HFOV}=$ high frequency oscillatory ventilation; $\mathrm{HFJV}=$ high frequency jet ventilation; $\mathrm{CV}=$ conventional ventilation; $\mathrm{RDS}=$ respiratory distress syndrome; $\mathrm{BPD}=$ bronchopulmonary dysplasia; $\mathrm{CLD}=$ chronic lung disease HLVS=high lung volume strategy; $\mathrm{RR}=$ relative risk; $\mathrm{CI}=$ confidence interval.

Table 5 Chronic lung disease: high frequency ventilation (HFV) versus conventional ventilation $(C V)$

\begin{tabular}{llll}
\hline $\begin{array}{l}\text { Reference } \\
\text { Clark, 1992 }\end{array}$ & $\begin{array}{l}\text { HFV event observed/ } \\
\text { total No of patients }\end{array}$ & $\begin{array}{l}\text { CV event observed/ } \\
\text { total No of patients }\end{array}$ & $\begin{array}{l}\text { Relative risk } \\
\text { (95\% CI) }\end{array}$ \\
Wiswell, 1996 & $3 / 30$ & $10 / 26$ & $0.26(0.08,0.84)$ \\
Keszler, 1997 & $6 / 37$ & $7 / 36$ & $0.83(0.31,2.24)$ \\
Rettwitz-Volk, 1998 & $11 / 55$ & $21 / 52$ & $0.50(0.27,0.92)$ \\
Plavka (in press) & $0 / 46$ & $0 / 50$ & Not estimable \\
Total for all studies & $4 / 21$ & $8 / 20$ & $0.48(0.17,1.34)$ \\
Total for HLVS subgroup & $24 / 189$ & $46 / 184$ & $0.49(0.32,0.75)$ \\
Total for surfactant subgroup & $18 / 106$ & $39 / 98$ & $0.43(0.26,0.70)$ \\
Total for HFOV subgroup & $7 / 97$ & $36 / 158$ & $0.56(0.35,0.89)$ \\
Total for HFJV subgroup & $17 / 92$ & $18 / 96$ & $0.35(0.16,0.77)$ \\
& & $28 / 88$ & $0.58(0.34,0.98)$
\end{tabular}

$\mathrm{HFV}=$ high frequency ventilation; HFOV=high frequency oscillatory ventilation; HFJV=high frequency jet ventilation; $\mathrm{CV}=$ conventional ventilation; $\mathrm{RDS}=$ respiratory distress syndrome; $\mathrm{BPD}=$ bronchopulmonary dysplasia; $\mathrm{CLD}=$ chronic lung disease; HLVS=high lung volume strategy; $\mathrm{RR}=$ relative risk; $\mathrm{CI}=$ confidence interval.

duration of mechanical ventilation, oxygen dependency and hospital stay; long term neurodevelopmental outcome and long term pulmonary outcome.

DATA SYNTHESIS AND SUBGROUP ANALYSES

Data extraction was done by a single author with a predefined data collection form. Data were subsequently imported in Revman 3.01 software for analysis. Meta-analysis was done using both a fixed effects model ${ }^{14}$ and a random effects model. ${ }^{15}$ Relative risks (RR) with $95 \%$ confidence interval (CI) were calculated. The assumption of comparable study populations due to poolings of relative risks was assessed based on the test on homogeneity of relative risks. Confidence intervals for relative risks that exclude unity should be considered significant. After the initial analysis of all included trials, subgroup analyses were performed. Four subgroups were determined before analysis according to the following criteria: subgroup 1 included all trials using a high lung volume strategy (HLVS); trials were considered to comply if it was clearly mentioned in the methods that HFV was started with a mean airway pressure (or continuous distending pressure) that was 1 to $2 \mathrm{~cm} \mathrm{H}_{2} \mathrm{O}$ higher than with convenitonal ventilation, or that alveolar recruitment was obtained by progressively increasing the mean airway pressure until inspired fraction of oxygen could be weaned below 0.30; subgroup 2 included all trials where surfactant replacement was given; subgroup 3 included all trials using high-frequency oscillators; and subgroup 4 included all trials using high frequency jet ventilators.

\section{Results}

Sixteen published articles of randomised controlled trials, ${ }^{6-10} 16-26$ one article in preparation ${ }^{11}$ and two abstracts, ${ }^{26}$ of which only one had been published, were identified. Two studies ${ }^{22} 24$ were excluded because study patients consisted mainly of term neonates with pulmonary diseases other than RDS. In two studies, ${ }^{17}$ (Ramanathan R, Ruiz I, Tantivit P, Cayabyab R, deLemos R. High frequency oscillatory ventilation compared to conventional mechanical ventilation in preterm infants with respiratory distress syndrome. Abstract, San Diego, CA: Society for Pediatric Research;1995) HFV was used for a limited time (48 hours and 96 hours, respectively), after which according to the study protocol patients were switched back to conventional ventilation. Three studies ${ }^{19-21}$ used $\mathrm{HFV}$ as a rescue treatment rather than as an elective mode of ventilation. One abstract was excluded because insufficient data were available on the methods of the trial at the time of data analysis. ${ }^{27}$ Nine published studies and one study in press met inclusion criteriaa ${ }^{6-11} 1618{ }^{2325}$; the characteristics of these studies and the results of the methodological assessment are shown in tables 1 and 2 .

Nine of the 10 studies mentioned mortality at the age of 28 to 30 days. Both in the overall analysis as well as in the subgroup analyses no significant difference was found (table 3). For the overall analysis the relative risk was 1.02 with a $95 \%$ CI between 0.78 and 1.35 . Nine studies explored the effect on bronchopulmonary dysplasia at the age of 28 to 30 days. There was no significant difference in BPD in the overall analysis [RR 0.91, (95\% CI: 0.80, 1.03)], nor in the subgroup analyses (table 4). For the HLVS subgroup the RR was 0.84, with a $95 \%$ CI between 0.69 and 1.02 .

Chronic lung disease at a postconceptional age of 36 weeks was described in five, more recent studies. There is a significant reduction in CLD both in the overall analysis [RR 0.50, (95\% CI: 0.32, 0.78)] and in the subgroup analyses (table 5). The reduction is most 
Table 6 Intraventricular haemorrhage grade 3 and 4: high frequency ventilation (HFV) versus conventional ventilation $(C V)$

\begin{tabular}{llll}
\hline Reference & $\begin{array}{l}\text { HFV event observed/ } \\
\text { total No of patients }\end{array}$ & $\begin{array}{l}\text { CV event observed/ } \\
\text { total No of patients }\end{array}$ & $\begin{array}{l}\text { Relative risk } \\
\text { (95\% CI) }\end{array}$ \\
\hline HIFI, 1989 & $84 / 327$ & $63 / 346$ & $1.41(1.06,1.88)$ \\
Clark, 1992 & $6 / 30$ & $6 / 26$ & $0.87(0.32,2.36)$ \\
Ogawa, 1993 & $2 / 46$ & $1 / 46$ & $2.00(0.19,21.30)$ \\
Gerstmann, 1996 & $2 / 56$ & $6 / 55$ & $0.33(0.07,1.55)$ \\
Wiswell, 1996 & $15 / 37$ & $8 / 36$ & $1.82(0.88,3.77)$ \\
Keszler, 1997 & $9 / 61$ & $9 / 59$ & $0.97(0.41,2.27)$ \\
Rettwitz-Volk, 1998 & $5 / 46$ & $2 / 50$ & $2.82(0.55,13.33)$ \\
Plavka (in press) & $0 / 21$ & $1 / 20$ & $0.32(0.01,7.38)$ \\
Total for all studies & $123 / 624$ & $96 / 638$ & $1.31(1.04,1.66)$ \\
Total for HLVS subgroup & $19 / 214$ & $23 / 206$ & $0.78(0.45,1.37)$ \\
Total for surfactant subgroup & $33 / 267$ & $27 / 266$ & $1.20(0.76,1.90)$ \\
Total for HFOV subgroup & $99 / 526$ & $79 / 543$ & $1.30(1.00,1.69)$ \\
Total for HFJV subgroup & $24 / 98$ & $17 / 95$ & $1.37(0.79,2.37)$ \\
\hline
\end{tabular}

$\mathrm{HFV}=$ high frequency ventilation; $\mathrm{HFOV}=$ high frequency oscillatory ventilation; $\mathrm{HFJV}=$ high frequency jet ventilation; $\mathrm{CV}=$ conventional ventilation; $\mathrm{RDS}=$ respiratory distress syndrome; $\mathrm{BPD}=$ bronchopulmonary dysplasia; $\mathrm{CLD}=$ chronic lung disease; HLVS=high lung volume strategy; $\mathrm{RR}=$ relative risk; $\mathrm{CI}=$ confidence interval.

Table 7 Periventricular leucomalacia: high frequency ventilation (HFV) versus conventional ventilation $(C V)$

\begin{tabular}{llll}
\hline Reference & $\begin{array}{l}\text { HFV event observed/ } \\
\text { total No of patients }\end{array}$ & $\begin{array}{l}\text { CV event observed/ } \\
\text { total No of patients }\end{array}$ & $\begin{array}{l}\text { Relative risk } \\
\text { (95\% CI) }\end{array}$ \\
\hline HIFI, 1989 & $38 / 327$ & $25 / 346$ & $1.61(0.99,2.60)$ \\
Ogawa, 1993 & $1 / 46$ & $4 / 46$ & $0.25(0.03,2.15)$ \\
Gerstmann, 1996 & $4 / 56$ & $3 / 55$ & $1.31(0.31,5.58)$ \\
Wiswell, 1996 & $10 / 32$ & $2 / 32$ & $5.00(1.19,21.04)$ \\
Keszler, 1997 & $4 / 61$ & $9 / 58$ & $0.42(0.14,1.30)$ \\
Rettwitz-Volk, 1998 & $1 / 46$ & $0 / 50$ & $3.26(0.14,77.97)$ \\
Plavka (in press) & $2 / 21$ & $1 / 20$ & $1.90(0.19,19.40)$ \\
Total for all studies & $60 / 589$ & $44 / 607$ & $1.39(0.96,2.02)$ \\
Total for HLVS subgroup & $11 / 184$ & $17 / 179$ & $0.63(0.30,1.30)$ \\
Total for surfactant subgroup & $22 / 262$ & $19 / 261$ & $1.13(0.63,2.02)$ \\
Total for HFOV subgroup & $46 / 496$ & $33 / 517$ & $1.45(0.95,2.22)$ \\
Total for HFJV subgroup & $14 / 93$ & $11 / 90$ & $1.24(0.59,2.61)$ \\
\hline
\end{tabular}

$\mathrm{HFV}=$ high frequency ventilation; $\mathrm{HFOV}=$ high frequency oscillatory ventilation; $\mathrm{HFJV}=$ high frequency jet ventilation; $\mathrm{CV}=$ conventional ventilation; $\mathrm{RDS}=$ respiratory distress syndrome; $\mathrm{BPD}=$ bronchopulmonary dysplasia; $\mathrm{CLD}=$ chronic lung disease; HLVS=high lung volume strategy; $\mathrm{RR}=$ relative risk; $\mathrm{CI}=$ confidence interval.

evident in the subgroup of high frequency oscillators [RR 0.35, (95\% CI: $0.16,0.77)$ ], and in the HLVS subgroup [RR 0.44, (95\% CI: $0.27,0.73)]$.

The incidence of IVH was mentioned in all but one trial, and the incidence of severe (grades 3 and 4) IVH was mentioned in eight trials. There was no difference in risk in the overall analysis [RR 1.09, (95\% CI: 0.96, 1.23)] or in the subgroup analyses. The risk of severe IVH was significantly higher in the HFV group, however, both when using the fixed effects model [RR 1.31, (95\% CI: 1.04, 1.66)], and the random effects model [RR 1.34, (95\% CI: 1.05, 1.70)] (table 6). Study outcomes all differed, however. The increased risk of severe IVH was only found in the HIFI trial [RR 1.41, (95\% CI: 1.06, 1.88)], which dominates this overall analysis here. The other trials did not find a higher risk. In the subgroup analyses the difference for severe IVH was not significant, although in the subgroup of high frequency oscillators, once again dominated by the HIFI trial, a trend towards an increased risk occurred [RR 1.30, (95\% CI: 1.00, 1.69)].

Of the 10 studies, seven report on the incidence of periventricular leucomalacia. In the overall analysis using the fixed effects model the RR is 1.39 (95\% CI: $0.96,2.02$ ), and with the random effects model the RR is 1.28 with a wider non-significant $95 \%$ confidence interval (95\% CI: 0.51, 3.19) (table 7). Again, this outcome varies among the studies. A higher risk for cystic PVL was evident in the study by Wiswell [RR 5.00, (95\% CI: 1.19, 21.04)]. In the HIFI trial a similar trend was present, with an RR of 1.61 (95\% CI: 0.99, $2.60)$. The other trials did not observe a difference.

All 10 studies report on the incidence of air leaks. There is no significant difference in risk for gross air leak and/or interstitial pulmonary emphysema in the overall analysis [RR 1.06, (95\% CI: 0.91, 1.23)], nor in the subgroup analyses. In the HIFI study an RR of 1.20 (95\% CI: 1.00, 1.43) for air leaks is observed in the HFV group, due to a higher incidence of pneumoperitoneum (3\% vs $1 \%$ in the conventional ventilation group).

Due to the fact that values on the duration of mechanical ventilation, oxygen dependency, and hospital stay were expressed differently in the studies - mean plus standard deviation or median with range - these data could not be pooled. Only in the study by Gerstmann was a significant reduction in duration of oxygen dependency for infants weighing more than 1 $\mathrm{kg}$ evident (median of 13.2 days vs 27.6 days for the HFV and CV group, respectively). In the same study the number of infants weighing $1 \mathrm{~kg}$ or less still on a ventilator on day 28 of life was significantly lower in the HFV group. In the other studies no significant differences were found in duration of oxygen dependency, mechanical ventilation, or hospital stay.

Only two studies report on the long term pulmonary outcome. In the HIFI trial a total 432 of 524 surviving study patients $(82 \%)$ were followed up and pulmonary function tests performed in 223 of them $(43 \%){ }^{27}$ There were no significant differences in incidence of episodes of wheezing, respiratory tract infections, or hospital readmissions. Impairment of pulmonary function was similar in both groups. Ogawa performed a chest $x$-ray of all his study infants at the age of 1 year. He found typical evidence of bronchopulmonary dysplasia in $2 \%$ of the HFV treated patients vs $4 \%$ in the conventionally ventilated patients, which was not significantly different. ${ }^{8}$

The same two studies comment on the long term neurodevelopmental outcome. In the HIFI trial 386 of the 504 survivors $(77 \%)$ were neurologically tested between the corrected age of 16 and 24 months. ${ }^{28}$ The proportion of children with a normal neurodevelopmental status (Bayley score of more than 83 and no major neurological defect) is significantly lower in the HFV group (54\% vs $65 \%$ in the conventional ventilation group). This is associated with a significantly higher incidence of hydrocephalus in the HFV group ( $12 \%$ vs $6 \%$ in the conventional ventilation group). No difference is observed in risk for, or severity of, cerebral palsy. Ogawa reports an identical incidence of developmental delay at the age of 1 year of $9 \%$ in both study groups.

\section{Discussion}

We used meta-analysis to address the question of efficacy and safety of the elective use of HFV in the treatment of RDS in preterm infants. All trials were rigorously assessed for their methodological quality. Several comments can be 
made. First, treatment allocation may not have been truly concealed, as this was done by the care provider in the centre where the patient was treated. In open trials true concealed allocation is only possible with central allocation by telephone and by a person not taking care of the patient, so that the patient is registered as a study patient before being allocated to a treatment group. Second, in these types of intervention studies blinding of the care providers is not possible, so all the included trials are sensitive for performance bias. Moreover, only two trials provided explicit guidelines for general patient management in the methods, ${ }^{68}$ reducing cointervention bias. In one study it was even stated that no attempt was made to control non-respiratory aspects of care. ${ }^{10}$ Blinding of outcome assessment can be achieved to a certain extent if the persons interpreting chest $x$-ray pictures or cerebral ultrasound scans are unaware of the treatment assignment of the patient. This was evidently not the case in all the studies and thus could lead to outcome detection bias in some studies. ${ }^{9} 10151624$

The results of the overall analysis are strongly influenced by the HIFI trial, which dominates the analysis due to its large study population. This trial has been criticised because the high lung volume strategy was not used. ${ }^{29}$ Investigators also probably lacked experience of the ventilators at that time. Animal studies confirm the advantages of a high lung volume strategy to minimise lung injury, ${ }^{230}$ and more recent, smaller clinical trials using this strategy show better pulmonary outcomes, without any increase in intracranial morbidity. ${ }^{9-11}$

It was suggested in the HIFI trial that the increased risk of severe IVH could be explained by obstructed venous return because of the continuous positive intrathoracic pressure. Yet this could not be confirmed by animal or human studies. ${ }^{31-33}$ Wiswell's HFJV trial showed a marked increase in periventricular leucomalacia in the HFV group. Mean $\mathrm{PaCO}_{2}$ concentrations were significantly lower in the HFV group, however, compared with the conventional ventilation group. The negative effects of hypocarbia on cerebral blood flow are described by Volpe and have been confirmed by Fujimoto and Wiswell. ${ }^{33-36}$ The results of the individual trials indicate that the therapeutic margin of this ventilation technique is very narrow, and that harm can be done if it is handled without sufficient experience or extensive monitoring.

By pooling all the data we increased the power of the evidence; heterogeneity between included studies, however, can impair the qualitative aspect of the analysis. Therefore, we tested for heterogeneity and performed subgroup analyses. Meta-analyses were performed by using both the Mantel-Haenszel approach ${ }^{14}$ and the DerSimonian and Laird technique. ${ }^{15}$ The former refers to the fixed-effects model and assumes that there is only one true effect of the intervention estimated by each study. The latter refers to the random-effects model and assumes that the studies are randomly taken from a population of studies and that there is a distribution of treatment effects, instead of a single true effect. When studies are homogeneous, the results of both fixed effects and random effects model will be similar; if there is significant heterogeneity between studies, however, the DerSimonian and Laird approach (random effects model) will be more conservative, resulting in larger confidence intervals around the estimate of the pooled RR, thus being more likely to find no significant difference between treatments.

For some of the outcomes we did find a strong heterogeneity in separate study results. As Marlow mentioned in his annotation, there are important differences among trials concerning the intervention and the study population, which could explain the variations in the outcomes. ${ }^{37}$ Different ventilators, as well as different ventilatory strategies were used for both types of ventilation. Four $\mathrm{HFV}$ frequencies going from $4 \mathrm{~Hz}^{18}$ up to $15 \mathrm{~Hz}^{6816}$ were used, and in the study by Wiswell and Keszler a low frequency background conventional ventilation was used. Conventional ventilation frequencies as low as 25 breaths per minute ${ }^{67}$ and as high as 60 breaths per minute ${ }^{910}$ were used. Mean birthweight and gestational age of the study infants varies between $900 \mathrm{~g}$ at 26 weeks and $1500 \mathrm{~g}$ at 31 weeks. ${ }^{911}$ The children's' postnatal age at which HFV was started also varies between 1.2 hours and 15.5 hours. ${ }^{18}{ }^{25}$ Marlow rightly stated that, supported by animal data, ${ }^{2}$ the very early use of HFV with a high lung volume strategy could be a very important factor in preventing lung injury and thus reducing chronic lung disease. ${ }^{37}$

We conclude from the meta-analysis that HFV does not improve survival of premature infants with RDS, but it does reduce the risk of chronic lung disease at 36 weeks of postconceptional age. It may be associated, however, with an increased risk of severe intraventricular bleeding. Yet, from the subgroup analysis there is evidence that, if a high lung volume strategy is used, the reduction of chronic lung disease may be more pronounced, and this favourable effect is achieved without increasing the risk of severe intraventricular haemorrhage.

Several areas of uncertainty remain. First, the hypothesis that a high lung volume strategy is associated with better outcome still requires confirmation with controlled trials of sufficient size, investigating both short term as well as long term pulmonary and neurological outcomes. Cohorts should be followed up long enough and at comparable postconceptional ages, and should be assessed with reproducible and standardised tests. Second, the outcome in very preterm infants (less than 30 weeks gestational age) and very low birthweight infants (birthweight less than $1000 \mathrm{~g}$ ), who are at highest risk of developing CLD and are most susceptible to neurological complications, is still to be investigated. Although most studies stratify their study patients according to birthweight, the results are usually not presented according to weight strata. Finally, as high frequency flow interrupters become widely used, randomised controlled trials investigating efficacy and safety of this technique of HFV are needed. 
We suggest that new clinical trials be done evaluating the usefulness of the elective use of HFV, started as soon as possible after birth, applied with a high lung volume strategy, in very premature infants (less than 30 weeks gestational age and/or weighing less than $1 \mathrm{~kg}$ ) and using the high-frequency flow interruptors. An optimal study design is important, such as centralised concealed treatment allocation, avoidance of cointervention bias, and blinding of outcome assessment. A consensus should be made on relevant outcomes so that results of these trials are of optimal quality and comparable with each other.

We thank R Plavka for providing his data, and A J M de Craen for critically appraising the manuscript.

1 Hack M, Horbar JD, Malloy M, Tyson JE, Wright E, Wright L. Very low birth weight outcomes of the National Institute of Child Health and Human Development Neonatal Network. Pediatrics 1991;87:587-97.

2 Meredith KS, de Lemos RA, Coalson JJ, et al. Role of lung injury in the pathogenesis of hyaline membrane disease in injury in the pathogenesis of hyaline membrane dise
premature baboons. 7 Appl Physiol 1989;66:2150-8.

3 Taskar V, John J, Evander E, Robertson B, Jonson B. Surfactant dysfunction makes lungs vulnerable to repetitive collapse and reexpansion. Am $f$ Crit Care Med 1997;155:313-20.

4 Bohn DJ, Miyasaka K, Marchak BE, Thompson WK, Froese AB, Bryan AC. Ventilation by high-frequency oscillation. $\mathcal{F}$ Appl Physiol 1980;48:710-6.

5 Jackson JC, Truog WE, Standaert TA, et al. Reduction in lung injury after combined surfactant and high-frequency ventilation. Am ₹ Respir Crit Care Med 1994;150:534-39.

6 HIFI study group. High-frequency oscillatory ventilation compared with conventional mechanical ventilation in the treatment of respiratory failure in preterm infants. $N$ Engl f Med 1989;320:88-93.

7 Clark RH, Gerstmann DR, Null DM, deLemos RA. Prospective randomized comparison of high-frequency Prospective randomized comparison of high-frequency
oscillatory and conventional ventilation in respiratory distress syndrome. Pediatrics 1992;89:5-12.

8 Ogawa Y, Miyasaka K, Kawano T, et al. A multicenter randomized trial of high frequency oscillatory ventilation as compared with conventional mechanical ventilation in preterm infants with respiratory failure. Early Hum Devel 1993;32:1-10.

9 Gerstmann DR, Minton SD, Stoddard RA, et al. The Provo multicenter early high-frequency ventilation trial: improved pulmonary and clinical outcome in respiratory distress syndrome. Pediatrics 1996;98:1044-57.

10 Keszler M, Modanlou HD, Brudno DS, et al. Multicenter controlled clinical trial of high-frequency jet ventilation in preterm infants with uncomplicated respiratory distress preterm infants with uncomplicated

11 Plavka R, Kopecký P, Sebroň V, Svilhovec P, Zlatohlávková $\mathrm{B}$, Januš $\mathrm{V}$. A prospective randomized comparison of conventional mechanical ventilation and high-frequency oscilventional mechanical ventilation and high-frequency oscillatory ventilation in treatment of respiratory distress
syndrome in extremely premature newborns. Int Care Med (In press)

12 Bhuta T, Henderson-Smart DJ. Elective high-frequency oscillatory ventilation versus conventional ventilation in preterm infants wiht pulmonary dysfunction: systematic review and meta-analyses. Pediatrics 1997;100. Available from: URL:http://www.pediatrics.org/cgi/content/full/100/ $5 / \mathrm{e} 6$.

13 The Cochrane Library (database on disk and CD ROM), The Cochrane Collaboration; Oxford Update Software; 1997 updated quarterly; available from BMJ Publishing

Group, London.
14 Fleis JL. The statistical basis of meta-analysis. Stat Methods Med Res 1993;2:121-45.

15 Der Simonian R, Laird N. Meta-analysis in clinical trials. Control Clin Trials 1986; 7:177-88.

16 Froese AB, Butler PO, Fletcher WA, Byford LJ. Highfrequency oscillatory ventilation in premature infants with 1987;66:814-24.
17 Carlo WA, Chatburn RL, Martin RJ. Randomized trial of high-frequency jet ventilation versus conventional ventilahigh-frequency jet ventilation versus conventional ventilation in respirat

18 Carlo WA, Siner B, Chatburn RL, Robertson S, Martin RJ. Early randomized intervention with high-frequency jet ventilation in respiratory distress syndrome. $f$ Pediatr 1990;117:765-70.

19 Keszler M, Donn SM, Bucciarelli RL, et al. Multicenter controlled trial comparing high-frequency jet ventilation and conventional mechanical ventilation in newborn infants with pulmonary interstitial emphysema. $\mathcal{F}$ Pediatr 1991;119:85-93.

$20 \mathrm{HiFO}$ study group. Randomized study of high-frequency oscillatory ventilation in infants with severe respiratory oscillatory ventilation in infants with severe
distress syndrome. F Pediatr 1993;122:609-19.

21 Pardou A, Vermeylen D, Muller MF, Detemmerman D. High-frequency ventilation and conventional mechanical ventilation in newborn babies with respiratory distress syndrome: a prospective, randomized trial. Intensive Care Med 1993;19:406-10

22 Clark RH, Yoder BA, Sell MS. Prospective, randomized comparison of high-frequency oscillation and conventional ventilation in candidates for extracorporeal membrane oxygenation. $\mathcal{F}$ Pediatr 1994;124:447-54

23 Wiswell TE, Graziani LE, Kornhauser MS, et al. Highfrequency jet ventilation in the early management of respiratory distress syndrome is associated with a greater risk for adverse outcomes. Pediatrics 1996;98:1035-43.

24 Engle WA, Yoder MC, Andreoli SP, Darragh RK, Langefeld CD, Hui SL. Controlled prospective randomised comparison of high-frequency jet ventilation and conventional ventilation in neonates with respiratory failure and persis ent pulmonary hypertension. F Perinatol 1997;17:3-9.

25 Rettwitz-Volk W, Veldman A, Roth B, et al. A prospective, randomized, multicenter trial of high-frequency oscillatory ventilation compared with conventional ventilation in preterm infants with respiratory distress syndrome receiving surfactant. F Pediatr 1998;132:249-54

26 Thome U, Gotze-Speer B, Speer CP, Pohland F. Comparison of pulmonary inflammatory mediators in preterm infants treated with intermittent positive pressure ventilation on high frequency oscillatory ventilation. Pediatr Res 1998:44:330-7.

27 HIFI study group. High-frequency oscillatory ventilation compared with conventional ventilation in the treatment of respiratory failure in preterm infants: Assessment of pulmonary function at 9 months of corrected age. 7 Pediatr 1990;116:933-41

28 HIFI study group. High-frequency oscillatory ventilation compared with conventional ventilation in the treatment of respiratory failure in preterm infants: Neurodevelopmental status at 16 to 24 months of posterm age. $\mathcal{F}$ Pediatr 1990:117:939-46.

29 Bryan AC, Froese AB. Reflections on the HIFI trial. Pediatrics 1991;87:565-7.

30 McCulloch PR, Forkert PG, Froese AB. Lung volume maintenance prevents lung injury during high-frequency maintenance prevents lung injury during high-frequency Rev Respir Dis 1988;137:1185-92.

31 Kinsella JP, Gerstmann DR, Clark RH, et al. Highfrequency oscillatory ventilation versus intermittent mandatory ventilation: early hemodynamic effects in the premature baboon with hyaline membrane disease. Pediatr Res 1991;29:160-6.

32 Schlösser RL, Rettwitz-Volk W, Allendorf A, Loewenich Vv. Hämodynamische Auswirkungen der hochfrequenten Oscillationsbeatmung bei Früh- und reifen Neugeborenen. Klin Pädiatr 1994;206:421-4.

33 Laubscher B, van Melle G, Fawer C-L, Sekarski N, Calame A. Haemodynamic changes during high-frequency oscillation for respiratory distress syndrome. Arch Dis Child 1996;74:F172-6.

34 Volpe JJ. Hypoxic ischemic encephalopathy: Biochemical and physiological aspects. In: Neurology of the newborn. $3 \mathrm{~d}$ edn. Philadelphia: W B Saunders Co, 1995: 240-1.

35 Fujimoto S, Togari H, Yamaguchi N, Mizutani F, Suzuki S, Sobajima H. Hypocarbia and cystic periventricular leukomalacia in premature infants. Arch Dis Child 1994;71:F107-10

36 Wiswell TE. Effects of hypocarbia on the development of cystic periventricular leukomalacia in premature infants treated with high-frequency jet ventilation. Pediatrics 1996;98:918-24.

37 Marlow N. High-frequency ventilation and respiratory distress syndrome: do we have an answer? Arch Dis Child 1998;78:F1-F2. 